\title{
ANÁLISE DA INCORPORAÇÃO DE RESÍDUOS EM MASSA CERÂMICA *
}

\author{
Alessandra Savazzini-Reis ${ }^{1}$ \\ Viviana Possamai Della Sagrillo \\ Francisco Rolando Valenzuela-Diaz ${ }^{3}$
}

\begin{abstract}
Resumo
A crescente preocupação em relação à sustentabilidade ambiental no setor de cerâmica vermelha associada ao alto consumo de argila, leva à busca de alternativas de incorporação de resíduos na massa argilosa. Com isso, vê-se a necessidade de caracterizar resíduos usados em cerâmica vermelha. As olarias brasileiras consomem cerca de 10 milhões de toneladas de argila ao mês para produção de telhas e blocos. O resíduo da indústria de rocha ornamental e a lama de alto forno podem se tornar passivos ambientais caso não sejam reaproveitados. O objetivo deste trabalho visa caracterizar e avaliar as propriedades cerâmicas em massas argilosas contendo resíduo de rocha e lama de alto forno. Os resíduos foram caracterizados por meio de ensaios de FRX, DRX, limites de Atterberg e granulometria. Massas argilosas com resíduos em teores variando de 5\% a 50\% (massa) foram conformadas, queimadas em forno industrial na olaria à $850^{\circ} \mathrm{C}$ para verificação de: absorção de água, porosidade, massa específica aparente, e resistência mecânica. Os resultados mostram que a massa argilosa com o resíduo de rocha no teor de $50 \%$ apresentou os melhores valores das propriedades cerâmicas analisadas e maior resistência mecânica, tais melhorias também foram verificadas na massa argilosa com lama de alto forno no teor de $5 \%$.
\end{abstract}

Palavras-chave: Resíduo de rocha ornamental; Lama de alto forno; Cerâmica vermelha; Incorporação.

\section{INCORPORATION ANALYSIS OF WASTE IN CERAMIC MASS}

\begin{abstract}
The growing concern about environmental sustainability in the red ceramic sector associated to high clay consumption, leads to the search for alternatives of incorporation of wastes in the clayey mass. With this, it is necessary to characterize wastes used in red ceramic products. The Brazilian pottery consumes about 10 million tons of clay a month for the production of roof tiles and blocks. The dimension stone industry waste and the blast furnace sludge can become environmental liabilities if they are not reused. The objective of this paper is to characterize and evaluate the ceramic properties in clayey masses containing dimension stone waste and blast furnace sludge. The wastes were characterized by XRF, XRD, Atterberg limits and granulometry. The clay and wastes in contents ranging from $5 \%$ to $50 \%$ (mass) were mixed and shaped into specimens for burning in industrial oven pottery at $850^{\circ} \mathrm{C}$ to check: water absorption, porosity, apparent specific mass and mechanical strength. The results showed that the clayey mass with dimension stone waste in the $50 \%$ content had the best values of the analyzed ceramic properties and greater mechanical strength; such improvements were also verified in the clayey mass with $5 \%$ of blast furnace sludge.
\end{abstract}

Keywords: Dimension stone waste; Blast furnace sludge; Structural ceramic; Incorporation. 
1 Engenheira Civil, Doutora, professora, Coordenadoria de Arquitetura e Urbanismo, IFES, Colatina, ES, Brasil.

2 Química Industrial, Doutora, professora, Coordenadoria de Metalurgia e Materiais, IFES, Vitoria, ES, Brasil.

3 Engenheiro Químico, Doutor, professor, PMT-EPUSP, São Paulo, SP, Brasil. 


\section{INTRODUÇÃO}

A crescente preocupação em relação à sustentabilidade ambiental no setor de cerâmica vermelha associada ao alto consumo de argila, principal matéria-prima das olarias, leva à busca de alternativas de incorporação de resíduos na massa argilosa. A argila é um material natural, terroso, de granulometria fina, que geralmente adquire plasticidade quando umedecido com água [1] e em proporções corretas forma uma massa plástica suscetível à modelagem para fabricação de produtos cerâmicos [2].

Em função da formação e fatores de alteração durante a sua consolidação, existe uma grande variedade de argilas com toda gama de cores, plasticidade e composição química [3], fatores esses que permitem a inserção de resíduos de diferentes processos industriais na mistura argilosa usada na cerâmica vermelha.

Sabe-se que a indústria de cerâmica vermelha brasileira consome cerca de 10 milhões de toneladas de argila ao mês para produção de blocos e telhas [4] que atendem ao setor da construção civil. A extração de argila para suprir as olarias é feita em jazidas de pequeno porte a céu aberto com escala de produção variando de 1.000 a 20.000 toneladas por mês com baixo valor de matéria-prima e alto custo de transporte [5].

Neste contexto, vê-se a necessidade de incorporar resíduos na massa argilosa para se fabricar produtos que consumam menos matéria-prima argilosa e, que também contribuam para diminuição do volume de resíduos dispostos em aterros [6]. Assim, o objetivo desta pesquisa é caracterizar e avaliar as propriedades cerâmicas em massas argilosas contendo resíduo de rocha ornamental e lama de alto forno.

\subsection{Resíduo de rocha ornamental em massa argilosa}

O resíduo de rocha ornamental é proveniente das indústrias de beneficiamento de granitos e mármores. Ele é gerado no corte dos blocos em chapas e no polimento dessas. O corte do bloco pode ser feito em tear de fios diamantados, neste caso o resíduo é constituído de pó da rocha e água. E o resíduo do bloco cortado em tear de lâminas metálicas acrescenta-se à mistura citada cal e granalha de aço. $O$ volume de resíduo gerado no corte do bloco representa $30 \%$ do seu volume total [710]. O resíduo do polimento é gerado na fase de tratamento superficial da chapa para dar brilho e fechar poros, esse resíduo é constituído por uma grande quantidade de água, pó de rocha e restos dos abrasivos utilizados, tal como, o carbeto de silício. Os dois resíduos são armazenados em silos e depois transportados e dispostos em aterros industriais. Em 2014, a quantidade de resíduo gerado na indústria brasileira de beneficiamento de rochas foi 3,65 milhões de toneladas [11].

Os resultados de pesquisas feitas com a incorporação de resíduo de rocha em massas argilosas mostram que nos teores entre $20 \%$ e $30 \%$ (massa) gera-se um aumento na densificação das peças com a melhoria na microestrutura; e o atendimento à resistência mecânica de blocos cerâmicos testados com $20 \%$ de resíduo [12-14].

O resíduo de rocha foi testado também em teores variando de 10\% a 90\% (massa) em massas argilosas, tendo sido obtido maior valor de resistência à flexão de corpos de prova no teor de $10 \%$. Contudo, no teor de $60 \%$ de resíduo de rocha a porosidade, a absorção de água e a perda ao fogo foram mínimas, e a massa específica foi máxima resultando em aumento de densificação [15]. 


\subsection{Lama de alto forno em massa argilosa}

A lama de alto forno é um dos resíduos gerados na produção do aço. A lama é gerada na etapa de limpeza à úmido dos gases gerados no alto forno. A empresa Arcelor Mittal, localizada em Serra no ES, gera mensalmente 4,5 mil toneladas de lama de alto forno [16] e cerca de 3,0 mil toneladas desse resíduo são comercializados para olarias do ES [17].

Em pesquisas feitas com a lama de alto forno incorporada em massas argilosas os melhores resultados de resistência mecânica e propriedades cerâmicas foram obtidos nos teores entre $3 \%$ e $5 \%$ (massa) [18-19].

\section{MATERIAIS E MÉTODOS}

O resíduo de rocha utilizado na pesquisa é proveniente das etapas de corte do bloco e polimento da chapa e foi cedido por indústria de beneficiamento de rochas ornamentais localizada na região noroeste do ES, enquanto a lama de alto forno é co-produto da siderúrgica Arcelor Mittal localizada em Serra-ES. A argila foi extraída em jazida na região noroeste do ES.

Amostras do resíduo de rocha, de lama de alto forno e de argila foram coletadas em pilha de armazenagem de matérias-primas em fábrica de cerâmica vermelha situada no Espírito Santo (Figura 1).

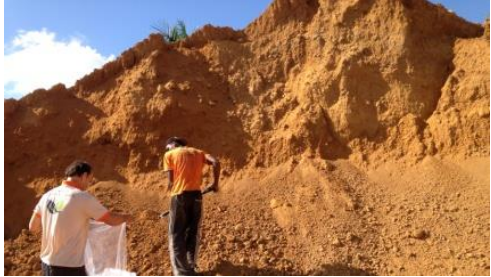

(a)

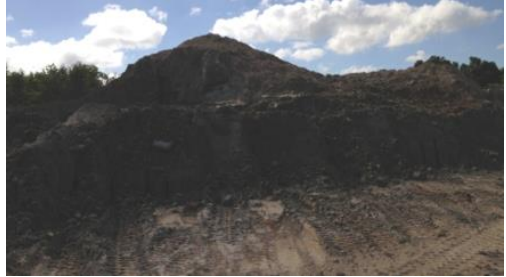

(b)

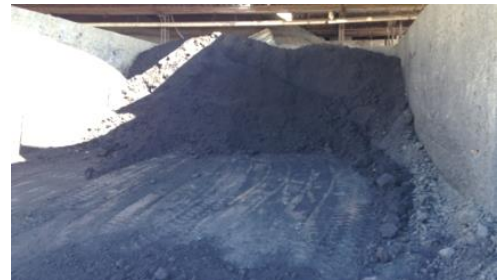

(c)

Figura 1. Coleta de: (a) Argila; (b) Resíduo de rocha; (c) Lama de alto forno

As amostras foram secas ao ar livre, destorroadas, homogeneizadas e quarteadas. Parte do material foi destinada para realização de ensaios de caracterização, e parte foi utilizada para confecção dos corpos de prova.

A caracterização das matérias-primas foi feita por meio de: fluorescência de raios $X$ (FRX) em espectrômetro marca Philips modelo PW2400; difração de raios X (DRX) com fonte de cobre (radiação $\mathrm{K} \alpha$ ) em aparelho Philips X-PERT MPD; limites de Atterberg segundo normas da ABNT [20-21]; e análise granulométrica por difração a laser em equipamento Mastersizer 2000 da Malvern. A identificação das amostras da DRX foi feita por comparação com arquivos do padrão Crystallographic Open Database (COD).

Após preparação inicial das matérias-primas, a argila (Figura 2 a), o resíduo de rocha (Figura 2 b) e a lama de alto forno (Figura $2 \mathrm{c}$ ) foram passados na peneira $\mathrm{n}^{-}$ 40 da ABNT (abertura de $0,42 \mathrm{~mm}$ ) para serem feitas misturas de argila e resíduo de rocha com teores variando de $10 \%$ a $50 \%$ (massa) e misturas de argila e lama de alto forno com teores variando de $5 \%$ a $50 \%$ (massa); que foram conformadas manualmente para obtenção de corpos de prova esféricos com massa seca de $10 \mathrm{~g}$, diâmetro médio de $2 \mathrm{~cm}$ e água suficiente para conformação, seguindo método desenvolvido no Laboratório de Materiais Não Metálicos Professor Persio de Souza Santos (LPSS) do PMT/EPUSP-BR. 
O uso da metodologia de conformação de esferas para análise das propriedades cerâmicas em misturas argilosas se dá em função de ser uma metodologia simples e de baixo custo que pode ser desenvolvida na própria olaria [22].

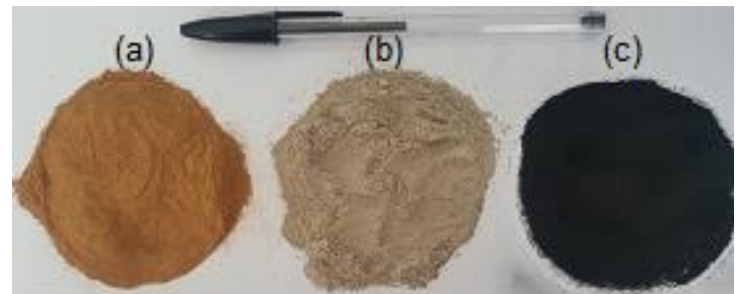

Figura 2. (a) Argila; (b) Resíduo de rocha; (c) Lama de alto forno, passados na peneira ABNT $n^{\circ}-40$

As esferas (Figura 3) foram queimadas em forno industrial contínuo tipo túnel por $24 \mathrm{~h}$ a uma temperatura máxima na zona de queima de $850^{\circ} \mathrm{C}$ em fábrica de cerâmica vermelha situada no ES.

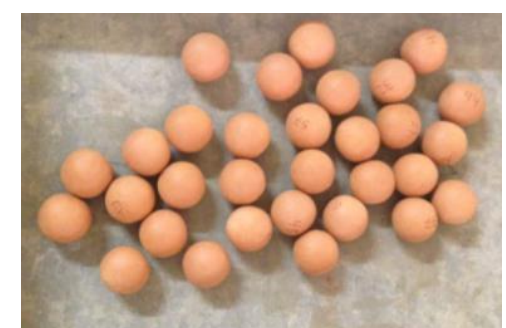

Figura 3. Esferas queimadas

A utilização do forno industrial da olaria teve como objetivo estabelecer condições ambientais e técnicas de fabricação para os corpos de prova da pesquisa semelhantes às utilizadas para os produtos cerâmicos.

As esferas queimadas foram submetidas a ensaios de absorção de água, porosidade aparente, massa específica aparente, perda de massa, de acordo com metodologia de Souza Santos [1], além da avaliação da retração volumétrica de queima e resistência à compressão.

\section{RESULTADOS E DISCUSSÃO}

\subsection{Utilização dos resíduos nas olarias}

A região noroeste do ES é considerada polo regional da indústria de cerâmica vermelha e conta com cerca de vinte empresas de pequeno e médio porte com produções de cerca de 50 mil a 1 milhão de peças ao mês. A pesquisa realizada nessa região do ES mostra que algumas olarias incorporam resíduo de rocha ornamental na massa argilosa e outras aproveitam a lama de alto forno, enquanto a maioria das indústrias não faz uso de resíduos nas misturas argilosas.

Nas olarias que aproveitam resíduos não existe controle eficaz da quantidade do resíduo que é incorporado e nem estudos de dosagem para se certificar da vantagem de ordem técnica e/ou econômica desse aproveitamento. Até mesmo a argila é escolhida de forma empírica baseando-se muitas vezes apenas em valores de limites de consistência. Tal prática é muito comum nas olarias do Espírito Santo, o que dificulta a padronização dos produtos finais. Grande parte das indústrias de 
cerâmica vermelha do Brasil apresenta o mesmo cenário do ES quanto à escolha e dosagem das matérias-primas. Essa situação no setor de cerâmica vermelha pode resultar em produtos cerâmicos não-conformes em relação às propriedades físicas e mecânicas estabelecidas nas Normas.

\subsection{Caracterização das matérias-primas}

O resultado da análise química das matérias-primas (Tabela 1) é apresentado em termos de percentual em peso dos óxidos constituintes.

A argila é constituída essencialmente de sílica e alumina, característica da matériaprima de cerâmica vermelha com caráter refratário, indicando a presença de caulinita e quartzo, com valores dentro do intervalo estipulado para $\mathrm{SiO}_{2}$ entre $43,2 \%$ e $77,6 \%$; e para o $\mathrm{Al}_{2} \mathrm{O}_{3}$ entre $6,8 \%$ e $38 \%$ [1].

O teor de ferro, de 9,29\% confere a cor avermelhada das peças após a queima, característica dos produtos de cerâmica vermelha.

Pode-se verificar que o resíduo de rocha apresenta uma composição química com predominância de sílica e alumina, com valores $62,88 \%$ e $14,11 \%$, respectivamente evidenciando ser um material sílico-aluminoso. A quantidade significativa de $\mathrm{SiO}_{2}$ está associada a fase cristalina do quartzo. Verifica-se também a presença dos óxidos alcalinos $\mathrm{K}_{2} \mathrm{O}$ e $\mathrm{Na}_{2} \mathrm{O}$ que por serem óxidos fundentes podem contribuir na queima da massa argilosa.

A lama de alto forno apresentou um elevado teor de ferro de $61,16 \%$, além de conter $\mathrm{SiO}_{2}, \mathrm{CaO}$ e $\mathrm{Al}_{2} \mathrm{O}_{3}$.

A perda ao fogo obtida da argila, de $13,17 \%$, se situou próximo ao limite máximo do intervalo de 6,0\% a 15,7\% específico para argilas cauliníticas [1]. Esta perda ao fogo relativamente alta apresentada pela argila está associada à desidroxilação dos argilominerais (caulinita) e à oxidação de matéria orgânica [23] e pode ocasionar elevada porosidade nas peças cerâmicas após queima [24-25].

O valor da perda ao fogo do resíduo de rocha de $2,97 \%$, pode ser considerado baixo comparado ao valor da argila de $13,17 \%$, o que indica ser um material que ocasiona baixa variação dimensional em peças submetidas à queima. Já a lama de alto forno apresenta uma alta perda ao fogo de $25,92 \%$, o que pode ser devido à combustão dos finos de coque que contém [26], resultando em aumento da porosidade nas peças queimadas.

Tabela 1. Composição química das matérias-primas por FRX

\begin{tabular}{c|c|c|c}
\hline \multicolumn{4}{c}{ Composição em óxidos (\% em peso) } \\
\hline Constituintes & Argila & $\begin{array}{c}\text { Resíduo de } \\
\text { rocha }\end{array}$ & $\begin{array}{c}\text { Lama de alto } \\
\text { forno }\end{array}$ \\
\hline $\mathrm{SiO}_{2}$ & 43,39 & 62,88 & 5,11 \\
\hline $\mathrm{Al}_{2} \mathrm{O}_{3}$ & 30,16 & 14,11 & 1,80 \\
\hline $\mathrm{Fe}_{2} \mathrm{O}_{3}$ & 9,29 & 5,72 & 61,16 \\
\hline $\mathrm{CaO}$ & 0,24 & 4,42 & 3,73 \\
\hline $\mathrm{K}_{2} \mathrm{O}$ & 1,25 & 4,36 & 0,23 \\
\hline $\mathrm{Na}_{2} \mathrm{O}$ & 0,17 & 2,54 & 0,06 \\
\hline $\mathrm{MgO}_{\mathrm{TiO}}$ & 0,62 & 1,02 & 0,70 \\
\hline $\mathrm{P}_{2} \mathrm{O}_{5}$ & 1,39 & 0,67 & 0,09 \\
\hline $\mathrm{BaO}$ & 0,12 & 0,38 & 0,13 \\
\hline $\mathrm{MnO}$ & 0 & 0,22 & 0,31 \\
\hline & 0,06 & 0,07 & 0,27 \\
\hline
\end{tabular}




\begin{tabular}{c|l|l|l}
\hline $\mathrm{ZnO}$ & 0 & $<0,1$ & 0,44 \\
\hline $\mathrm{Co}_{2} \mathrm{O}_{3}$ & 0 & $<0,1$ & $<0,1$ \\
\hline $\mathrm{Cr}_{2} \mathrm{O}_{3}$ & 0 & $<0,1$ & $<0,1$ \\
\hline $\mathrm{PbO}$ & 0 & $<0,1$ & $<0,1$ \\
\hline $\mathrm{SrO}$ & 0 & $<0,1$ & $<0,1$ \\
\hline $\mathrm{ZrO}_{2}+\mathrm{HfO}_{2}$ & 0 & $<0,1$ & $<0,1$ \\
\hline
\end{tabular}

O difratograma de raios $\mathrm{X}$ das matérias-primas está apresentado na Figura 4.

Nas argilas, pode-se observar que os picos de difração predominantes correspondem a caulinita, tendo sido detectados também ilita e quartzo. Além de indícios da presença de goetita e de gibsita. A presença de caulinita obtida no DRX confirmou o resultado da FRX, pois em geral, a argila com elevado teor de alumina apresenta a caulinita como principal argilomineral [27], além da plasticidade encontrada.

Quanto a gibsita, ela sofre uma transformação pseudomórfica em temperaturas em torno de $260^{\circ} \mathrm{C}$, o que pode contribuir para aumentar a refratariedade da argila e a perda de massa [7]. A fase cristalina goetita foi justificada pelo alto teor de ferro detectado na FRX e confere cor avermelhada, pois oxida em hematita.

Quanto ao resíduo de rocha, verificou-se a presença de quartzo, feldspato, mica e calcita; principais minerais constituintes das rochas ornamentais, tal como, o granito [28]. O quartzo (forma cristalina do $\mathrm{SiO}_{2}$ encontrado na análise química) pode causar redução na plasticidade de massas argilosas; a calcita confirma o $\mathrm{CaO}$ encontrado na FRX; enquanto o feldspato e a mica podem atuar como fundentes na queima das peças cerâmicas.

O DRX da lama de alto forno identificou fases cristalinas associadas aos compostos de ferro, tais como a magnetita e hematita corroborando o alto teor de $\mathrm{Fe}_{2} \mathrm{O}_{3}$ da FRX. Foram identificados ainda quartzo e calcita.

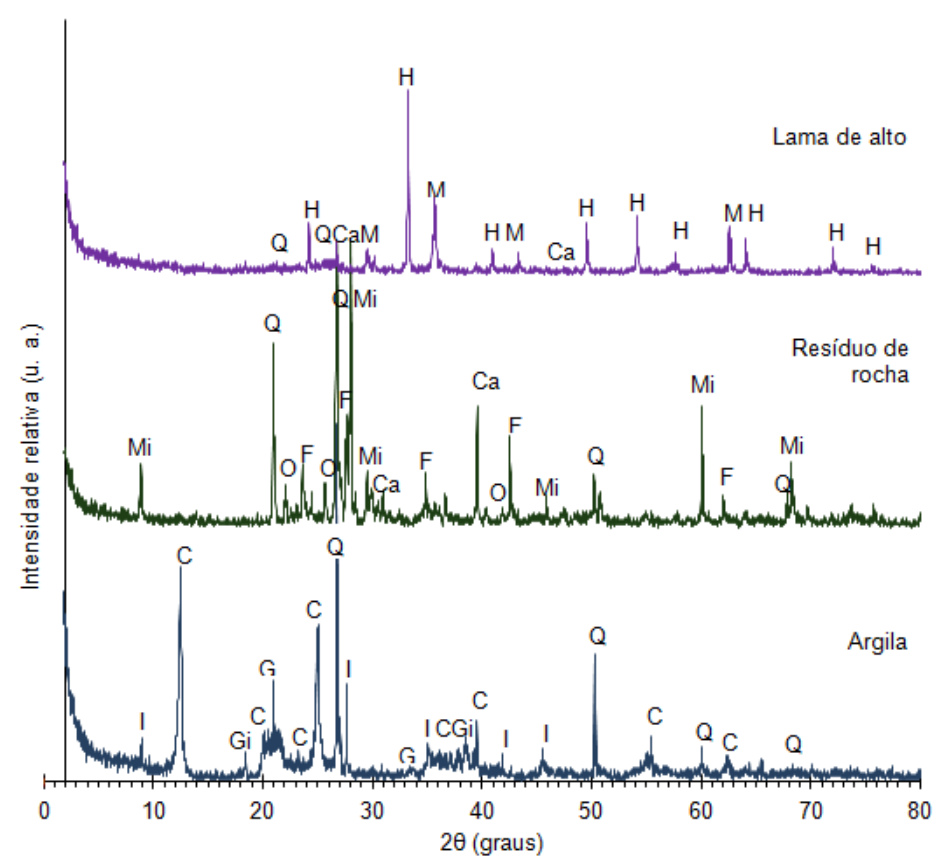

Figura 4. DRX das matérias-primas

Nota: C - caulinita (COD 1011045); Ca - calcita (COD 9009667); F - feldspato (COD 9001898); G - goetita (COD 1008768); Gi - gibsita (COD 1200016); H - hematita (COD 1011240); I - ilita (COD 9013718); M magnetita (COD 9013530); Mi - mica (COD 9000819); O - ortoclásio (COD 9006347); Q - quartzo (COD 9012602) 
Os limites de Atterberg e a granulometria são apresentados na Tabela 2.

O índice de plasticidade (IP) da argila, de $21,24 \%$, se situa dentro da faixa estipulada de variação de $8,9 \%$ e 56,3\% para argilas cauliniticas [1]. Esse valor do índice de plasticidade (IP), maior que 15, indica que a argila possui alta plasticidade [29], o que pode demandar maior quantidade de água para extrusão e maior tempo de secagem.

Foram feitas tentativas para se determinar o limite de plasticidade do resíduo de rocha, mas os experimentos foram impraticáveis, assim como ocorreu no trabalho de Moreira, Freire e Holanda (2003) [30]. Com isso, o resíduo de rocha se comporta como um material não plástico.

A lama de alto forno apresentou um IP de 9,12\%, valor entre 7 e 15 [29], o que indica ser pouco plástica. Além disso, por ser um valor menor que 10, pode ser difícil o processo de extrusão de peças com a lama de alto forno [25].

$\mathrm{Na}$ distribuição de tamanho de partículas (granulometria) das matérias-primas (Tabela 2) verifica-se que os resíduos e a argila possuem baixa "fração argila" (grãos menores que $2 \mu \mathrm{m}$ ). Com isso, a alta plasticidade apresentada pela argila pode ser função da presença de matéria orgânica e da fração de tamanhos de partículas associadas ao silte ( $2 \mu \mathrm{m}$ a $20 \mu \mathrm{m})$.

Tabela 2. Caracterização física das matérias-primas

\begin{tabular}{c|c|c|c|c|c|c}
\hline \multirow{2}{*}{ Características } & \multicolumn{3}{|c|}{ Limites de Atterberg (\%) } & \multicolumn{3}{c}{ Granulometria (\%) } \\
\cline { 2 - 7 } & LL & LP & IP & $<\mathbf{2 \mu m}$ & $\mathbf{2 - 2 0 \mu m}$ & $\mathbf{2 0} \boldsymbol{\mu m}$ \\
\hline Argila & 59,61 & 38,37 & 21,24 & 7 & 55 & 38 \\
\hline $\begin{array}{c}\text { Resíduo de } \\
\text { rocha }\end{array}$ & 28,07 & N.D. & N.P. & 10 & 50 & 40 \\
\hline $\begin{array}{c}\text { Lama de alto } \\
\text { forno }\end{array}$ & 44,20 & 35,08 & 9,12 & 10 & 45 & 45
\end{tabular}

Nota: LL=limite de liquidez; LP=limite de plasticidade; IP=indice de plasticidade; N.D.=não determinado; N.P.=não plástico

\subsection{Propriedades das matérias-primas}

Os resultados encontrados das propriedades cerâmicas e da resistência mecânica das esferas feitas com as matérias-primas estão apresentados na Tabela 3.

Pode-se verificar que a argila apresenta menores valores de absorção de água e porosidade aparente. E maiores valores de: perda ao fogo, massa específica aparente e resistência à compressão quando comparada aos valores do resíduo de rocha.

Já os corpos de prova feitos com lama de alto forno se quebraram durante a queima em várias tentativas, não sendo assim possível a determinação das suas propriedades.

Tabela 3. Propriedades das esferas com as matérias primas

\begin{tabular}{c|c|c|c|c|c|c}
\hline Matérias primas & $\mathbf{P F}(\%)$ & $\mathbf{A A}(\%)$ & $\mathbf{P A}(\%)$ & $\mathbf{M E A}\left(\mathbf{g} / \mathbf{c m}^{\mathbf{3}}\right)$ & $\mathbf{R V}(\%)$ & $\boldsymbol{\sigma}(\mathbf{M P a})$ \\
\hline Argila & 11,86 & 25,21 & 37,41 & 1,52 & 3,80 & 1,31 \\
\hline Resíduo de rocha & 3,63 & 26,21 & 38,47 & 1,50 & $-0,41$ & 0,07 \\
\hline Lama de alto forno & n.d. & n.d. & n.d. & n.d. & n.d. & n.d. \\
\hline
\end{tabular}

Nota: $P F=$ perda ao fogo; $A A=$ absorção de água; $P A=$ porosidade aparente; $M E A=$ massa especifica aparente; $R V=$ retração volumétrica; $\sigma=$ resistência à compressão; n.d.=não determinado 
Foi feita a incorporação de cada resíduo na massa argilosa nos teores de $10 \%, 20 \%$, $30 \%, 40 \%$ e $50 \%$ (massa) para avaliação das propriedades cerâmicas e mecânica nas esferas. Além do teor de $5 \%$ (massa) para a lama de alto forno. As Tabelas $4 \mathrm{e}$ 5 apresentam os resultados encontrados.

$\mathrm{Na}$ Tabela 4, que apresenta os resultados da massa argilosa incorporada com resíduo de rocha ornamental, observa-se que os valores de: perda ao fogo (PF), retração volumétrica de queima (RV), absorção de água ( $A A)$ e porosidade aparente (PA) diminuíram com o aumento do teor do resíduo. Sendo que os mínimos valores de absorção e porosidade foram encontrados no teor de 50\% (massa); enquanto a massa específica aparente (MEA) foi máxima nesse teor. Com isso, pode-se dizer que em $50 \%$ (massa) de resíduo de rocha na massa argilosa, os corpos de prova apresentaram uma maior densificação, que pode ter ocorrido em função do preenchimento dos poros intersticiais dos grãos das argilas pelo resíduo, que atua como um "enchimento" promovendo o empacotamento físico dos grãos.

O resíduo de rocha pode ter promovido uma maior estabilidade dimensional nos corpos de prova durante a queima em função da diminuição nos valores apresentados de retração volumétrica e perda ao fogo, fato relatado também em outras pesquisas [31-32].

Os valores de resistência à compressão após a queima $(\sigma)$ diminuíram com o aumento do teor do resíduo de rocha, provavelmente devido ao aumento do teor de quartzo, presente no resíduo, que causa pontos de fratura diminuindo a resistência mecânica nos corpos de prova.

Tabela 4. Propriedades das esferas com argila e resíduo de rocha ornamental

\begin{tabular}{c|c|c|c|c|c|c}
\hline $\begin{array}{c}\text { Teor de } \\
\text { resíduo(\%) }\end{array}$ & PF(\%) & AA(\%) & PA(\%) & MEA(g/cm $\mathbf{c m}^{\mathbf{3}}$ & $\mathbf{R V ( \% )}$ & $\boldsymbol{\sigma}(\mathbf{M P a})$ \\
\hline 10 & 11,55 & 24,54 & 36,19 & 1,52 & 4,13 & $\mathbf{1 , 9 2}$ \\
\hline 20 & 9,81 & 23,68 & 35,94 & 1,52 & 3,94 & 1,68 \\
\hline 30 & 8,01 & 23,56 & 35,89 & 1,52 & 3,92 & 1,49 \\
\hline 40 & 7,68 & 23,37 & 35,59 & 1,53 & 3,25 & 1,04 \\
\hline 50 & $\mathbf{6 , 9 3}$ & $\mathbf{2 3 , 3 2}$ & $\mathbf{3 5 , 4 6}$ & $\mathbf{1 , 5 3}$ & $\mathbf{3 , 2 3}$ & 0,77 \\
\hline
\end{tabular}

Nota: $P F=$ perda ao fogo; $A A=$ absorção de água; $P A=$ porosidade aparente; $M E A=$ massa especifica aparente; $R V=$ retração volumétrica; $\sigma$ = resistência à compressão

De acordo com a Tabela 5, que ilustra o comportamento dos corpos de prova da argila com incorporação da lama de alto forno, observa-se que os valores de perda ao fogo (PF), absorção de água (AA), porosidade aparente (PA), retração volumétrica de queima (RV) aumentaram com o aumento do teor da LAF. Já o valor da massa específica aparente (MEA) diminuiu. A máxima resistência à compressão $(\sigma)$ nos corpos de prova queimados foi encontrada no teor de $5 \%$ (massa) de resíduo. A partir daí, os valores de resistência à compressão diminuíram com o aumento do teor de LAF. Este comportamento pode ser atribuído à composição mineralógica da LAF, pois a hematita permanece inerte durante a queima e os finos de coque aumentam a porosidade da massa argilosa. Esses resultados indicam o uso de baixos teores de LAF em massa argilosa. 
Tabela 5. Propriedades das esferas com argila e lama de alto forno

\begin{tabular}{c|c|c|c|c|c|c}
\hline $\begin{array}{c}\text { Teor de } \\
\text { resíduo(\%) }\end{array}$ & PF(\%) & AA(\%) & PA(\%) & MEA(g/cm $)^{3}$ & $\mathbf{R V ( \% )}$ & $\boldsymbol{\sigma}(\mathbf{M P a})$ \\
\hline 5 & $\mathbf{1 2 , 9 0}$ & $\mathbf{2 5 , 2 7}$ & $\mathbf{3 7 , 5 2}$ & $\mathbf{1 , 5 0}$ & $\mathbf{3 , 7 2}$ & $\mathbf{2 , 0 0}$ \\
\hline 10 & 14,24 & 25,59 & 37,89 & 1,50 & 4,46 & 1,69 \\
\hline 20 & 14,90 & 26,79 & 38,66 & 1,47 & 5,27 & 1,60 \\
\hline 30 & 18,01 & 30,24 & 42,80 & 1,42 & 6,54 & 1,57 \\
\hline 40 & 18,36 & 31,69 & 42,91 & 1,41 & 6,65 & 1,18 \\
\hline 50 & 21,01 & 31,76 & 43,09 & 1,40 & 6,85 & 0,97 \\
\hline
\end{tabular}

Nota: $P F=$ perda ao fogo; $A A$ = absorção de água; $P A=$ porosidade aparente; $M E A=$ massa especifica aparente; $R V=$ retração volumétrica; $\sigma=$ resistência à compressão

\section{CONCLUSÃO}

A caracterização química e mineralógica da argila demonstrou que o argilomineral predominante é a caulinita, pode ser considerada sílico-aluminosa e contém teores de quartzo e de ferro adequados para fabricação de cerâmica vermelha. Com um valor de perda ao fogo relativamente alto.

O resíduo de rocha ornamental apresenta alto teor de sílica que promove a estabilidade dimensional nos corpos de prova confirmada com os baixos valores encontrados de retração de queima e perda ao fogo, porém pode gerar pontos de fratura devido a presença do quartzo, o que resulta em perda da resistência mecânica, apesar da densificação que promove.

A lama de alto forno possui alto teor de ferro e alta perda ao fogo que pode ocasionar aumento de porosidade nas peças queimadas.

As matérias-primas apresentam granulometria com baixo teor da fração argila, sendo que a argila possui alta plasticidade, que pode ser corrigida com os resíduos em questão, em função da lama de alto forno apresentar baixa plasticidade e o resíduo de rocha ornamental não ser plástico.

Os resultados mostram que os corpos de prova da massa argilosa incorporada com o resíduo de rocha ornamental no teor de $50 \%$ (massa) apresentaram melhoria na densificação das peças, porém diminuição da resistência mecânica. Já a lama de alto forno apresenta melhores valores das propriedades analisadas no teor de $5 \%$ (massa). Tais resultados poderiam ser melhorados com o aumento da temperatura de queima acima de $850^{\circ} \mathrm{C}$, a qual é utilizada no forno da olaria, onde foram queimados os corpos de prova, entretanto tal medida resultaria em aumento do custo de produção.

Com isso, a incorporação dos resíduos analisados na massa argilosa pode ser uma alternativa ambientalmente sustentável para a indústria de cerâmica vermelha, a de rochas ornamentais e a siderúrgica. É importante ressaltar a importância de desenvolver estudos das misturas argilosas incorporadas com resíduos a serem usadas nas olarias para resultarem em produtos que atendam às Normas pertinentes.

\section{Agradecimentos}

Agradecimentos ao IFES, Finep e ao PMT/EPUSP. 


\section{REFERÊNCIAS}

1 Souza Santos P. Tecnologia das argilas. Vol.1-2. São Paulo: Edgard Blucher, 1975.

2 Callister WD. Ciência e engenharia de materiais: uma introdução. 5a edição. Rio de Janeiro: LTC, 2002. 589p.

3 Petrucci EGR. Materiais de construção. 4를 Edição. Porto Alegre: Editora Globo; 1979. 435p.

4 Associação Nacional da Indústria Cerâmica (ANICER). Dados oficiais. RJ. 2016. [Acesso em 24 març. 2017]. Disponível em: http://www.anicer.com.br/index.asp?pg= institucional. asp\&secao $=3 \&$ categoria $=60 \&$ selMenu $=4$.

$5 \quad$ Ministério do Desenvolvimento, Indústria e Comércio Exterior do BR (MDIC) Cerâmica vermelha - Termo de referência. [Acesso em 14 abr. 2016]. Disponível em: http://www.mdic.gov.br/arquivos/dwnl_1295436730.pdf.

6 Reis AS, Della-Sagrillo VP,Valenzuela-Diaz FR. Green structural ceramic with addition of raw clay waste. In: TMS145th Annual Meeting \& Exhibition. Nashville -Tennessee EUA. 2016. 6p.

7 Vieira CMF, Sales HF, Monteiro SN. Effect of illitic flux clay addition in red ceramic of kaolinitic clays. Revista Cerâmica, São Paulo, n. 50, p. 239-246, 2004.

8 Mello ISC, Cuchierato G, Motta JFM, Consoni Â J, Reis FAGV, Muniz JMC. Aproveitamento dos resíduos sólidos das serrarias de rochas ornamentais e para revestimento. Estudo de caso: Emigran Pisos e Revestimentos em granitos. IPT. São Paulo. 2006.

9 Cavalcanti DJH. Contribuição ao estudo de propriedades do concreto auto-adensável visando sua aplicação em elementos estruturais. 2006. 141 p. Dissertação (Mestrado) - Universidade Federal de Alagoas, Maceió, 2006.

10 Reis AS, Alvarez CE. A sustentabilidade e o resíduo gerado no beneficiamento das rochas ornamentais. In: II Encontro Latino-Americano sobre Edificações e Comunidades Sustentáveis - ELECS, 2007, Mato Grosso do Sul. Anais... Mato Grosso do Sul: ANTAC, 2007. CD-ROM.

11 ASSOCIAÇÃO BRASILEIRA DA INDÚSTRIA DE ROCHAS ORNAMENTAIS (ABIROCHAS). Balanço das exportações, importações, produção e consumo interno brasileiro de rochas ornamentais em 2014. Informe 01/2015. São Paulo. 2015. [acesso em 24 març. 2017]. Disponível em: http://www.ivolution.com.br/mais/fotos/6/17/3397/Informe_01_2015.pdf.

12 Souza AJ, Pinheiro BCA, Holanda JNF. Efeito da adição de resíduo de rocha ornamental nas propriedades tecnológicas e microestrutura de piso cerâmico vitrificado. Revista Cerâmica, São Paulo, v. 57, p. 212-218, 2011.

13 Ferreira LC. Potencial de utilização de resíduos industriais na formulação de massa de cerâmica vermelha para a fabricação de blocos de vedação. 2012. 76 p. Dissertação (Mestrado) - Universidade Federal do Paraná, Paraná, 2012.

14 Bildhauer DC, Bruxel FR, Santana ERR, Oliveira EC. Tijolos maciços com características refratárias a partir da incorporação de resíduo de mármore e granito. Revista Liberato, v.16, n.25, p.73-83, 2015. [acesso em: 23 març. 2017]. Disponível em: http://www.liberato.com.br/sites/default/files/arquivos/Revista_SIER/v.16,\%20 n.25\% 20(2015)/08-tijolos.pdf.

15 Reis AS, Sagrillo VPD, Valenzuela-Diaz FR. Influencia da adição de resíduo de granito em massa argilosa usada na produção de telhas cerâmicas. In: $21^{\circ}$ Congresso Brasileiro de Engenharia e Ciência dos Materiais - CBECIMAT, 2014, Cuiabá. Anais... Cuiabá: CBECIMAT, 2014.

16 ARCELOR MITTAL BRASIL (2014). [acesso em 12 agosto 2014]. Disponível em: http://cst.com.br/produtos/co_produtos/catalogo_produtos/lama/lama.asp.

17 Mothé AV. Utilização da lama de alto forno em cerâmica vermelha. 2008. 100f. Dissertação (Mestrado) - Universidade Estadual do Norte Fluminense - RJ. 2008. 
18 Reis AS, Sagrillo VPD, Valenzuela-Diaz FR. Estudo da viabilidade técnica de incorporação de lama de alto forno em massa argilosa. In: 69 Congresso Anual da ABM, 2014, São Paulo. Anais... São Paulo: ABM, 2014.

19 Lima LHM, Reis SC, Borges LR. Aproveitamento de resíduo siderúrgico em blocos cerâmicos argilosos. Revista E-xacta, Belo Horizonte, v.5, n.2, p.69-78. 2013. [acesso em 20 març. 2017]. Disponível em: http://revistas.unibh.br/index.php/dcet/ article/view/1073/612.

20 Associação Brasileira de Normas Técnicas (ABNT). NBR 6459: Solo - determinação de limite de liquidez. Rio de Janeiro, 1984.

21 . NBR 7180: Solo - determinação do limite de plasticidade. Rio de Janeiro, 1984.

22 Miyahara RY, Furlan GHRH, Valenzuela-Diaz FR, Toffoli SM. Correlação entre medidas de resistência mecânica de corpos de prova de argila conformados manualmente e por prensagem uniaxial. In: 48ํㅡㄹ Congresso Brasileiro de Cerâmica, 2004, Curitiba. Anais... Curitiba: ABCERAM, 2004.

23 Dias CACM. Reciclagem de lama de alto-forno em cerâmica vermelha. 2011. 142 p. Tese (Doutorado) - Universidade Estadual Norte Fluminense, Rio de Janeiro, 2011.

24 Vieira CMF, Peçanha LA, Monteiro SN. Efeito da incorporação de resíduo de serragem de granito em massa de cerâmica vermelha. Vértices. Ano 5. n.3, p.143-157, set/dez 2003. [acesso em 10 març. 2017]. Disponível em: http://www.essentiaeditora.iff.edu.br/ index.php/vertices/article/view/1809-2667.20030024/114.

25 Vieira CMF, Pinheiro RM. Evaluation of kaolinitic clays from Campos dos Goytacazes used for red ceramic fabrication. Revista Cerâmica, São Paulo, n. 57, p. 319-323, 2011.

26 Vieira CMF, Dias CACM, Mothé AV, Sánchez R, Monteiro SN. Incorporation of blast furnace sludge into red ceramic. Revista Cerâmica, São Paulo, n. 53, p. 381-387, 2007.

27 Sales Jr JCC. Avaliação da potencialidade de argilas de queima clara como matériasprimas para o desenvolvimento de novos produtos cerâmicos. 2008. 94 p. Dissertação (Mestrado) - Universidade Federal do Rio Grande do Norte, 2008.

28 Manhães JPVT, Moreira JMS, Holanda JNF. Variação microestrutural de cerâmica vermelha incorporada com resíduo de rocha ornamental. Revista Cerâmica, São Paulo, v. 55 , p. $371-378,2009$.

29 Caputo HP. Mecânica dos solos e suas aplicações. 6ª edição. v1. Rio de Janeiro: LTC, 2011. 234p.

30 Moreira JMS, Freire MN, Holanda JNF. Utilização de resíduo de serragem de granito proveniente do Espírito Santo em cerâmica vermelha. Revista Cerâmica. São Paulo, v. 49, p.262-267, 2003.

31 Taguchi SP, Santos JC, Gomes TM, Cunha NA. Evaluation of technological properties of red ceramics incorporated with dimension Stones waste from diamond wire loom. Revista Cerâmica, São Paulo, v.60, p. 291-296, 2014.

32 Reis AS. Produção de telha cerâmica com incorporação simultânea de resíduo de beneficiamento de granito, lama de alto forno e resíduo de massa cerâmica crua. 2015. 122 p. Tese (Doutorado) - PMT/EPUSP- Universidade de São Paulo (USP). SP. 2015. 